\title{
Cultura material, progresso, civilização e identidade nacional: Os caminhos de ferro coloniais em Angola e Moçambique
} (c. 1870 - C. 1915) ${ }^{1}$

\begin{abstract}
Resumo
A partir de começos da década de 1870, Portugal iniciou nas suas colónias ultramarinas um esforço de fomento semelhante ao que vinha aplicando no território metropolitano desde 1851. Até às vésperas da Primeira Guerra Mundial, milhares de quilómetros de carris foram assentes tanto em Angola como em Moçambique. Neste artigo, pretendemos analisar este processo de implementação tecnológica como produtor de uma nova cultura material. Mostraremos que esta cultura material, que espelhava as crenças metropolitanas de progresso assentes na tecnologia, procurou influenciar as populações africanas locais e as demais nações coloniais europeias. No final, tentou contribuir para a implementação de uma identidade nacional na África Portuguesa e para facilitar a colonização económica e sobretudo cultural dos domínios ultramarinos nacionais. Para atingir estes objetivos, recorreremos a fontes textuais diversas (debates parlamentares, relatórios técnicos, textos de diplomas legais) e a fontes iconográficas, guardadas em diversos arquivos portugueses e estrangeiros.

Palavras-chave: Nacionalismo Tecnológico. Saint-simonismo. Colonização. Iconografia.
\end{abstract}

\section{Para citar este artigo:}

PEREIRA, Hugo Silveira. Cultura material, progresso, civilização e identidade nacional: Os caminhos de ferro coloniais em Angola e Moçambique (c. 1870 - c. 1915). Tempo e

Argumento, Florianópolis, v. 11, n. 27, p. 221 - 254, maio/ago. 2019.

\section{DOI: $10.5965 / 2175180311272019221$}

http://dx.doi.org/10.5965/2175180311272019221

\footnotetext{
* Nesse texto optou-se por manter a grafia da língua nativa (Língua Portuguesa - Portugal).

${ }^{1}$ Financiado por Fundos Nacionais: bolsa de pós-doutoramento SFRH/BPD/95212/2013, decreto-lei 57/2016 e lei $57 / 2017$
}

Doutor em História pela Universidade do Porto. Investigador auxiliar no Centro Interuniversitário de História das Ciências e da Tecnologia (Universidade NOVA de Lisboa); Honorary Visiting Fellow no Institute of Railway Studies (Universidade de York). Caparica - PORTUGAL hugojose.pereira@gmail.com orcid.org/0000-0002-7706-2686 


\title{
Material culture, progress, civilization and national identity: Colonial railways in Angola and Mozambique (c. 1870-c. 1915)
}

\begin{abstract}
Since the early 1870s, Portugal applied in its overseas colonies a developmental agenda like that employed in the metropolitan territories since 1851. Up until the eve of World War I, thousands of miles of rails were built both in Angola and Mozambique. In this paper we aim to analyse this process of technological implementation as a producer of a new material culture. We seek to demonstrate that this material culture that reflected the beliefs on progress through technology sought to influence the local African populations and the several European colonial nations. In the end it aimed to contribute to imprinting the national identity in Africa and to facilitate the economical and mainly cultural colonization of the Portuguese overseas domains. To achieve these goals, we will analyse sundry primary textual sources (parliamentary debates, technical reports, laws and decrees) and iconographic material preserved in several archives in Portugal and abroad.
\end{abstract}

Keywords: Technological Nationalism. Saint-Simonianism. Colonization. Iconography.

\section{Introdução}

Não há como os factos materiais, complicados [...] e incompreensíveis aos espíritos sem cultura, [...] que firam a imaginação do selvagem, promovendo-lhe a admiração pela raça branca e o reconhecimento da sua superioridade. Um revolver [...], uma máquina a vapor $[\ldots]$, um caminho-de-ferro, o silvo e o movimento de uma locomotiva [...] produzem no indígena da África acção muito mais eficaz para os efeitos do seu aperfeiçoamento intelectual, do que muitas missas e pregações do mais virtuoso missionário - Joaquim José Machado, engenheiro (1879, apud NAVARRO, 2018, p. 320). 
A partir da segunda metade do século XIX, a abertura de grandes sistemas tecnológicos (redes ferroviárias, telegráficas, elétricas) foi um elemento marcante na construção ocidental, indelevelmente influenciada pelo ideário saint-simoniano de progresso (LAAK, 2010; VAN DER VLEUTEN, 2006). Eles simbolizavam o desenvolvimento, a bitola pela qual se media o valor civilizacional das diferentes nações (ADAS, 1989; ADAS, 2006; SCHOT;SCRANTON, 2014) e a excelência dos países do centro da Europa face ao subdesenvolvimento das periferias (SIMÕES et al., 2003).

Nos territórios africanos e asiáticos, tecnologias como o quinino, os barcos a vapor, o armamento, o telégrafo e os caminhos de ferro desempenharam um papel fulcral na penetração, conquista e consolidação da presença europeia naquelas áreas e sua aproximação ao centro europeu (HEADRICK, 1981). A já existente superioridade técnica europeia foi reforçada e incentivou o domínio das regiões ultramarinas, sujeitas a partir de então a um novo imperialismo (ADAS, 1989; HEADRICK, 2010).

Dentre estas tecnologias, a que nos interessa é o caminho de ferro, que, desde a década de 1830 e graças à ação do engenheiro Michel Chevalier, se tornou um elemento fulcral da ideologia saint-simoniana (VAN DER VLEUTEN, 2006; VAN DER VLEUTEN et al., 2007), que tanto influenciou as elites técnicas portuguesas (MACEDO, 2012). A ferrovia, à sua aptidão para transportar mercadorias e pessoas rapidamente e a longas distâncias, aliava uma elevada capacidade simbólica e política de reforço da identidade nacional nos locais onde era implementada, através da criação de uma nova cultura material (NYE, 1999; MACEDO, 2012; SARAIVA, 2007) - conceito que "emphasises how apparently inanimate things within the environment act on people, and are acted upon by people, for the purposes of carrying out social functions, regulating social relations and giving symbolic meaning to human activity" (WOODWARD, 2007, p. 3).

Por exemplo, em Inglaterra, o caminho de ferro contribuiu para a formação da identidade do rural Englishness (PAYNTON, 1996). Na Suíça, o túnel ferroviário de Saint Gothard foi durante décadas "a symbol of the country's independence" (SCHUELER, 2006, p. 82-87). No contexto colonial, a estação de Bombaim representava poder, orgulho e a naturalização do sistema ferroviário imposto por Inglaterra ao território (KERR, 2003). Nos domínios europeus em África, a ferrovia assumiu-se como instrumento 
determinante de afirmação de direitos de soberania e de europeização do território (BLANCHARD;LEMAIRE, 2003; DIOGO, 2009; HALL, 2002; LEE, 1999).

Além de tudo isto, o caminho de ferro oferecia igualmente uma forte componente visual, que aliás justificou a atração que sempre exerceu sobre pintores e fotógrafos (ADAS, 2006; SARAIVA, 2007). Hobsbawm descrevia-o como "o símbolo mais espectacular desta era [século XIX]” (HOBSBAWM, 1979, p. 63), “por onde deslizavam cobras com plumas de fumo à velocidade do vento" (HOBSBAWM, 1982, p. 66). No contexto oitocentista português, o engenheiro Silva Costa opinava que "nada é mais maravilhoso do que um trem voando [...] sobre um caminho de ferro" (DIARIO DO GOVERNO, 22 maio 1857, p. 690).

Estas expressões, além de demonstrarem a crença nas capacidades desenvolvimentistas da tecnologia (em particular da ferrovia), evidenciavam o sentimento de sublime técnico, o prazer retirado de observar uma máquina em funcionamento, como símbolo máximo do triunfo tecnológico do Homem (KASSON, 1976), que, por sua vez, contribuía para a homogeneização de sociedades multiculturais (NYE, 1999).

A construção de uma nova cultura material proporcionada pelos caminhos de ferro refletia-se, por fim, na marca que deixavam na paisagem, transformando-a em paisagem tecnológica. Este conceito foi analisado por Jackson e Nye e decorre do entendimento segundo o qual a paisagem não é uma realidade natural, mas sim cultural, com elementos humanos e não-humanos (LATOUR, 2004; MITCHELL, 2002) e inseparável das tecnologias que configuram o território (JACKSON, 1984; NYE, 1999)².

Nesta conceptualização epistemológica, a fotografia desempenhou um papel fundamental, "a connective tissue between humanity and world", já que a paisagem "as a social practice has $[. .$.$] vested much of its fate in photographic reproduction" (KELSEY,$ 2016, p. 71, p. 90). A fotografia, além de fundamental na exploração do continente

\footnotetext{
${ }^{2}$ Ver, para os casos concretos das linhas do Douro e Tua, em Portugal: MACEDO, Marta Coelho de. Projectar e construir a nação: engenheiros e território em Portugal. Lisboa: Imprensa de Ciências Sociais, 2012; SPERO, Ellan; PEREIRA, Hugo Silveira. The Tua Valley in transition, symbol and technological landscape. Cultura, Espaço e Memória, Porto, n. 7, p. 223-241, 2016.
} 
africano (MARTINS, 2012), e na imposição de uma ideologia colonial (MATOS, 2016), foi também decisiva para construir paisagens tecnológicas, divulgar o sublime técnico (NYE, 1999), tornar visível um "novo território racional, ordenado e produtivo" (MACEDO, 2012, p. 307) e constituir uma "iconography of nationhood" (OSBORNE, 1988).

Neste artigo pretendemos laborar sobre estes conceitos e demonstrar de que forma o caminho de ferro foi utilizado na África Portuguesa como promotor da identidade nacional através do fomento de uma cultura material, ao serviço do esforço imperialista português, no período compreendido entre os primeiros esforços de fomento no ultramar (c. 1870) e as vésperas da Primeira Guerra Mundial, prosseguindo na senda de trabalhos recentes sobre esta matéria (DIOGO, 2009; DIOGO;LAAK, 2016; DIOGO;NAVARRO, 2018; NAVARRO, 2018), que realçaram o papel da tecnologia (ferroviária e não só) e dos engenheiros portugueses no processo colonizador luso. Pretendemos ainda contribuir para uma caracterização da mentalidade portuguesa da época, tendo em conta que uma sociedade não pode ser interpretada sem consideração pelos seus objetos materiais e que as suas formas distintivas são caracterizadas pela sua própria cultura material (DANT, 1999). Recorreremos para tal a discursos parlamentares, relatórios, pareceres, e preâmbulos de leis redigidos por engenheiros e políticos e ainda a fotografias da construção e da operação ferroviárias guardadas em arquivos portugueses e estrangeiros.

Deste modo, iremos privilegiar necessariamente as perceções dos agentes metropolitanos portugueses. Com isto não queremos, porém, insinuar que o projeto colonialista luso foi aceite passivamente pelas populações nativas. Pelo contrário, a resistência à presença do colono português em África foi real e intensa, como bem o demonstram as diversas guerras que opuserem ambas as partes durante os séculos XIX e XX (PÉLISSIER, 2004). Aliás, urge na historiografia ouvir as vozes nativas preservadas tanto nos arquivos coloniais como nos arquivos africanos e analisar as suas próprias representações sobre a colonização ${ }^{3}$. Neste sentido, reconhecemos que o estudo que agora apresentamos peca por não incluir tais vozes. No entanto, tendo em conta o

\footnotetext{
3 Veja-se, para um exemplo metodológico: BASTIAN, Jeannette Allis. Reading Colonial Records Through an Archival Lens: The Provenance of Place, Space and Creation. Archival Science, Dordrecht, v. 6, p. 267-284, 2006.
} 
estado presente da nossa investigação, a nossa facilidade de acesso aos arquivos ultramarinos europeus e a própria natureza deste tipo de artigos (de dimensão necessariamente reduzida), focar-nos-emos apenas na visão portuguesa e metropolitana sobre aqueles processos (realçando o papel da ferrovia), abrindo, porém, a porta para novas pesquisas que incluam as visões nativas sobre o mesmo objeto histórico.

\section{A estratégia ferroviária nacional para as colónias}

Considerando que neste momento [...] as nações mais poderosas se mostram empenhadas em abrir ao commercio de todo o mundo as regiões maravilhosas da Africa Central, é indispensavel que sem perda de tempo ponhamos o remate a esta obra do caminho de ferro de [Ambaca]. - Pinheiro Chagas, ministro da Marinha e Ultramar (1884, COLLECÇÃO OFFICIAL DE LEGISLAÇÃO PORTUGUEZA, 1884, p. 535, itálico nosso).

A partir de inícios da década de 1870, Portugal tomou as primeiras medidas para estabelecer serviços de obras públicas ultramarinos e assim aplicar um programa de melhoramentos materiais, baseado no paradigma europeu que privilegiava a técnica e a ciência modernas, nos seus domínios africanos. Nas décadas seguintes, seriam construídos milhares de quilómetros de caminhos de ferro em Angola (linhas de Ambaca, Moçâmedes e Benguela) e Moçambique (Lourenço Marques, Beira, Suazilândia, Quelimane, Xai-Xai e Inhambane), sendo muitos outros projetados, mas nunca construídos ${ }^{4}$.

Um dos objetivos subjacentes ao projeto ferroviário era modernizar o sistema de transportes colonial e explorar as imaginadas riquezas do sertão, respondendo ao mito do Eldorado (ALEXANDRE; DIAS, 1998), na promoção de uma cultura mais materialista que material. Desta operação, esperava-se a geração de um tráfego suficiente que redundaria na recuperação do investimento feito. Era, aliás, a aplicação do modelo usado por outras nações coloniais desde 1850 e intensificado a partir de 1870 (DAY, 1963;

\footnotetext{
${ }^{4}$ Para a história das ferrovias construídas no período colonial em Angola e Moçambique, ver: NAVARRO, Bruno J. Um império projectado pelo «silvo da locomotiva»: o papel da engenharia portuguesa na apropriação do espaço colonial africano Angola e Moçambique (1869-1930). Lisboa: Colibri, 2018.
} 
DIVALL, 2009; HEADRICK, 1981; KERR, 2007) e também a forma matricial da própria estratégia de investimento portuguesa (ALEGRIA, 1988).

Em 1876, o ministro do Ultramar, Andrade Corvo, evocava as "riquezas naturaes do solo" e a "grandeza quasi illimitada das forças produtivas" dos domínios africanos para justificar a construção de um caminho de ferro de Luanda ao interior (DIARIO DA CAMARA DOS DEPUTADOS, 2 março 1876, p. 503). A Sociedade de Geografia de Lisboa, uma das principais promotoras do fomento colonial (GUIMARÃES, 1984), confirmava que tal empreendimento, "sob o ponto de vista do emprego de capitaes, parece [...] uma empreza não só em extremo viavel, mas de lucros certos e importantes" (COMISSÃO AFRICANA, 1882 p. 143-170). Anos mais tarde, um outro titular da pasta colonial, Ressano Garcia, descrevia a "riquissima região que a Companhia de Moçambique tem de explorar", como justificativo para lhe ceder várias isenções para construir uma ferrovia (LEGISLAÇÃO..., 1895-1908, vol. 1, 389.). Estas miríficas expectativas não se concretizaram, embora seja inegável que os caminhos de ferro introduziram francas melhorias nos transportes coloniais, com impacto direto sobre o aumento dos volumes transportados e sobre o desenvolvimento de produções locais.

Em Angola, quando a linha de Ambaca atingiu $150 \mathrm{~km}$ de extensão (1890), transportou pouco menos de 3.000 t de mercadorias. Mas em 1909, quando chegou a Malange, já carregava quase 28.000 t (CAMINHOS DE FERRO, LUANDA, 1912; CAMINHOS DE FERRO, MALANGE, 1907-1909; CAMINHOS DE FERRO, LUANDA, AMBACA, MALANGE E MORMUGÃO..., 1905-1916; CAMINHOS DE FERRO, MALANGE, MAPAS ESTATÍSTICOS..., 1912; CAMINHOS DE FERRO, MALANGE E MOÇÂMEDES..., 1907-1916; MISCELÂNEA, CAMINHOS DE FERRO, S. TOMÉ..., 1888-1914; ESTATÍSTICA..., 1913). Mais a sul, em Moçâmedes, as cerca de 1.000 t transportadas no ano da inauguração dos primeiros 73 km (1907) cresceram para 64.000 t em 1914, altura em que a linha já se internava 147 km na região (CAMINHOS DE FERRO, MOÇÂMEDES, 1910-1916; CAMINHOS DE FERRO, MOÇÂMEDES, 1906-1908; CAMINHOS DE FERRO, MOÇÂMEDES, 1913-1917; CAMINHOS DE FERRO, MOÇÂMEDES, 1909-1910; CAMINHOS DE FERRO, LUANDA, 1902-1920; CAMINHOS DE FERRO, MOÇÂMEDES, 1907-1914; CAMINHOS DE FERRO, MOÇÂMEDES, RECEITA..., 1913; CAMINHOS DE FERRO, MOÇÂMEDES, RECEITA..., 1904-1908; MISCELÂNEA, 
CAMINHOS DE FERRO, S. TOMÉ..., 1888-1914; ESTATÍSTICA..., 1913; PEREIRA, 2018b). Os primeiros números da linha de Benguela indicam um volume de cerca de $21.000 \mathrm{t}$ transportadas no primeiro ano de operação (1909 com 197 km). Quatro anos e 163 km depois a carga era já de 47.500 t (MISCELÂNEA, DIRECÇÃO..., 1889-1923; MISCELÂNEA, CAMINHOS DE FERRO, S. TOMÉ..., 1888-1914). Este aumento na capacidade de transporte permitiu o desenvolvimento de alguns negócios locais ligados ao café (em Ambaca), minério (Moçâmedes) e borracha (Benguela).

Estes números refletiram-se parcialmente no movimento da alfândega que entre 1888 e 1913 subiu de cerca de 6.500 para 12.500 contos, com picos de 15.000 e 18.250 contos em 1899 e 1910 (MESQUITA, 1918).

Em termos de transportes de passageiros, as linhas contribuíram também para uma maior mobilidade no território. Em Benguela, o número de viajantes duplicou de 30.000 para 60.000 nos anos indicados, enquanto em Moçâmedes o crescimento foi de 400\% de 4.000 para 20.000. Ambaca foi uma exceção, tendo a evolução de movimento acompanhado o ritmo do assentamento da via; assim que este parava, o movimento de passageiros - leia-se trabalhadores - ressentia-se (CAMINHOS DE FERRO, LUANDA, 1912; CAMINHOS DE FERRO, MALANGE, 1907-1909; CAMINHOS DE FERRO, LUANDA, AMBACA, MALANGE E MORMUGÃO..., 1905-1916; CAMINHOS DE FERRO, MALANGE, MAPAS ESTATÍSTICOS..., 1912; CAMINHOS DE FERRO, MALANGE E MOÇÂMEDES..., 1907-1916; CAMINHOS DE FERRO, MOÇÂMEDES, 1910-1916; CAMINHOS DE FERRO, MOÇÂMEDES, 1906-1908; CAMINHOS DE FERRO, MOÇÂMEDES, 1913-1917; CAMINHOS DE FERRO, MOÇÂMEDES, 1909-1910; CAMINHOS DE FERRO, LUANDA, 1902-1920; CAMINHOS DE FERRO, MOÇÂMEDES, 1907-1914; CAMINHOS DE FERRO, MOÇÂMEDES, RECEITA..., 1913; CAMINHOS DE FERRO, MOÇÂMEDES, RECEITA..., 1904-1908; ESTATÍSTICA..., 1913; MISCELÂNEA, CAMINHOS DE FERRO, S. TOMÉ..., 1888-1914; MISCELÂNEA, DIRECÇÃO..., 1889-1923).

Contudo, em termos de investimento financeiro, os resultados ficaram muito aquém do desejado: as companhias que exploravam as linhas de Ambaca e Benguela viviam em constantes dificuldades pecuniárias e a exploração dos caminhos de ferro de Moçâmedes e Malange pelo Estado acumulava défices (NAVARRO, 2018). 
Em Moçambique, verificou-se algo semelhante, mas com alguns cambiantes. A linha de Lourenço Marques, que, nos primeiros dez anos de exploração (1889-1898) fez uma modesta média anual de $41.000 \mathrm{t}$, atingiu um volume recorde superior a 1.000.000 t em 1913 (registando evolução idêntica em termos de transporte de passageiros), graças sobretudo ao ouro das minas do Transval. Em consequência, tornou-se um dos empreendimentos mais lucrativos em todo o sector ferroviário nacional (MISCELÂNEA, CAMINHOS DE FERRO, S. TOMÉ..., 1888-1914: QUESTÃO..., 1887-1918; ESTATÍSTICA..., 1913; BOUENE; SANTOS, 2006). Sobre a linha da Beira não existem dados seguros sobre a sua operação, uma vez que ela foi assegurada por uma companhia britânica que praticamente não partilhava informações estatísticas com as autoridades portuguesas (NAVARRO, 2018). Contudo, o seu efeito sobre as províncias de Manica e Sofala está bem patente nos dados da alfândega da Beira, cujo movimento comercial passou de 192 contos em 1892, ano do início da construção da linha, para 133.000 contos em 1914, 14 anos depois de a linha estar completa (BOLETIM DA COMPANHIA DE MOÇAMBIQUE, 1893-1910; BOLETIM DO GOVERNO DO TERRITÓRIO DA COMPANHIA DE MOÇAMBIQUE, 1911-1915; BOLETINS ESTATÍSTICOS DO MOVIMENTO COMERCIAL E MARÍTIMO NO TERRITÓRIO DE MANICA E SOFALA; 1908-1909; BOLETINS ESTATÍSTICOS DO MOVIMENTO COMERCIAL E MARÍTIMO NO TERRITÓRIO DA COMPANHIA DE MOÇAMBIQUE, 1910; PEREIRA, 2019). O impacto dos demais caminhos de ferro moçambicanos foi mais reduzido em virtude da sua curta extensão, pobreza das regiões atravessadas e caráter inteiramente provincial, não se ligando às colónias vizinhas (NAVARRO, 2018).

Além deste objetivo eminentemente económico-comercial, Portugal procurava ainda com a construção de caminhos de ferro em África atingir fins políticos e de “regeneração espiritual” (para usar a expressão de NYE, 1999, p. XX), que são, aliás, os que mais interessam neste estudo: construir uma cultura material de matriz tecnológica, que legitimasse a sua presença nas colónias africanas, respondendo ao mito da herança sagrada (ALEXANDRE; DIAS, 1998), imprimisse a identidade nacional em espaços longínquos e civilizasse os povos autóctones. 


\title{
3. O caminho de ferro como cultura material e promotor do ideário europeu de civilização e progresso
}

\begin{abstract}
Se trouxermos a uma estação de caminho de ferro o homem menos civilisado, menos culto, um hottentote, ou um cannibal, e lhe mostrarmos uma locomotiva, emblema da magestade industrial, producto admiravel das artes mechanicas, ser quasi pensante, este homem enthusiasmou-se necessariamente pelos caminhos de ferro, e o seu primeiro desejo é levar esses caminhos para a sua terra. - Belchior Garcês, deputado (1860, DIARIO DA CAMARA DOS DEPUTADOS, 23 março 1860, p. 249).
\end{abstract}

A ideia de usar o caminho de ferro como instrumento de apropriação territorial das colónias ("through a repetitive and consistent use of an area by a certain person or group who, at least to some extent, perceive this area as their own", de acordo com a definição de Kärrholm (2012, p. 16; p. 137-138) decorria de esforço semelhante realizado na metrópole desde 1850 e replicava o modelo usado por outras nações coloniais, como vimos. Na retórica parlamentar, técnica e jornalística que acompanhou esta agenda tecnológica, tanto no que se referia às metrópoles europeias como às colónias, os termos progresso/prosperidade e civilização eram amiúde mencionados (HEADRICK, 1981).

Por exemplo, na década de 1870, o Colonial Office britânico, ponderando uma possível tomada de posse do distrito de Lourenço Marques de mãos portuguesas, considerava que uma ferrovia no território contribuiria "enormously to the civilisation of Eastern Africa" (ELTON, 17 julho 1875, p. 3). O Tesouro inglês estava igualmente convicto de que tal linha

could not fail to ensure the prosperity if the new Province [Lourenço Marques] [was] added to Her Majesty's Dominions and promote the happiness and welfare of its inhabitants and would thus aid in the work of civilizing the populations of South Africa (BREWER, 5 fevereiro 1878).

Em Portugal, igual fé estava bem expressa no decreto de 1 de dezembro de 1869, que reformava a administração ultramarina e, numa "techno-scientific view of progress" (DIOGO; LAAK, 2016, p. 149), associava o desenvolvimento e a civilização das colónias à implementação de melhoramentos materiais, designadamente as vias de comunicação que encurtavam a distância para a metrópole (NAVARRO, 2018). 
Esta representação perdurou ao longo de todo o período analisado. Em 1883, Andrade Corvo mantinha que "a civilização moderna [e] todo o progresso moral e material depende das fáceis comunicações; das estradas, dos caminhos de ferro, dos telégrafos eléctricos" (apud NAVARRO, 2018, p. 77). Em 1890, no parlamento, o deputado Alberto Pimentel classificava o caminho de ferro de "fiscal da civilização" (DIARIO DA CAMARA DOS DEPUTADOS, 24 julho 1890, p. 1484). No final do século, os engenheiros e jurisconsultos reunidos na Junta Consultiva do Ultramar, órgão consultivo do Ministério da Marinha e Ultramar (responsável pela gestão das colónias), ao analisar a linha de Moçâmedes, entendiam que esta contribuiria igualmente "para a grande empreza da civilisação da Africa" (JUNTA CONSULTIVA DO ULTRAMAR, 10 agosto 1899). Por fim, em 1901, o capitão de engenheiros, Henrique César da Silva Barahona e Costa, acreditava que

a questão das obras publicas [...] não só tem alta importancia economica, mas principalmente se pode considerar uma questão politica, porque d'ella deriva o engrandecimento da nação, o crescimento da riqueza publica e o progresso da civilização (COSTA, 1901, p. 429, itálico nosso).

A imposição de uma cultura material através dos caminhos de ferro no sentido de trazer o progresso e a civilização a África fez-se num duplo sentido, tendo em conta (1) a própria nação portuguesa e sua relação com as demais nações coloniais da Europa e (2) os povos africanos.

\subsection{O caminho de ferro como garante da soberania nacional no Ultramar}

Além de levar o progresso e a civilização aos confins de África, a ferrovia teria o condão de transportar Portugal da periferia tecnológica para o seu centro. Ao construir caminhos de ferro nas paisagens africanas e ali consolidar a presença de uma cultura material e tecnológica, Portugal equiparava-se às nações do centro europeu que desde 1850 vinham fazendo o mesmo nas suas próprias colónias. Isto mesmo fica demonstrado no excerto do decreto de 10 de dezembro de 1884 com que abrimos o capítulo 2 deste artigo. No preâmbulo ao diploma, Pinheiro Chagas lembrava a urgência em construir o caminho de ferro de Ambaca uma vez que "os importantes problemas da civilização 
africana" eram uma questão com que "hoje toda a Europa culta se preoccupa" (COLLECÇÃO OFFICIAL DE LEGISLAÇÃO PORTUGUEZA, 1884, p. 535, itálico nosso). Nas entrelinhas ficava implícito que só os povos incultos, atrasados e periféricos não se preocupavam com a civilização de África. O carácter periférico era considerado injurioso e conduzia a um sentimento de exclusão (com uma significância cultural e simbólica e não apenas económica) e a uma necessidade de ligação ao centro (SHILS, 1975; SWARTZ, 1997).

Simultaneamente, a ferrovia era igualmente considerada uma das melhores soluções para competir com as demais nações coloniais europeias no scramble for Africa (PAKENHAM, 2011) e assim contrariar as suas ambições expansionistas e a sua cobiça sobre os domínios ultramarinos nacionais. Após a conferência de Bruxelas (1876) e sobretudo após a de Berlim (1884-1885), a implementação de caminhos de ferro nas colónias portuguesas de África foi visto como o meio mais eficaz de solidificar a ocupação efetiva e, consequentemente, a soberania nacional sobre aqueles territórios africanos (DIOGO, 2009).

As ambições internacionais, sobretudo as britânicas, ficam bem patentes num editorial publicado no The Railway Times em 1881, que reforça também o caráter civilizador do caminho de ferro. Naquele diário, podia ler-se que

it must be borne in mind that Africa cannot any longer be neglected by them [os portugueses], as all the European nations have now commenced to diffuse the light of civilization over the face of that «dark» continent (THE RAILWAY TIMES, 5 novembro 1881, p. 1041).

No ano seguinte, quase como que em resposta ao texto britânico, a Sociedade de Geografia de Lisboa emitia um parecer sobre o projetado caminho de ferro de Luanda a Ambaca, considerando-o precisamente "a mais solene [...] garantia de soberania e de ocupação civilizadora" (AMARAL, 1882, p. 3).

Esta preocupação acentuou-se nos anos imediatamente a seguir ao Ultimato Britânico de 1890, pelo qual Inglaterra exigiu a retirada das forças portuguesas dos territórios entre Angola e Moçambique, sob pena de corte de relações diplomáticas. Na reformulação da estrutura de administração de Moçambique, surgida por decreto de 30 
de setembro de 1891 e em resposta àquele incidente diplomático (NAVARRO, 2018; ver também DIOGO; LAAK, 2016), o ministro da Marinha e Ultramar, Júlio de Vilhena, via no caminho de ferro uma das melhores formas de confirmar a presença nacional em Moçambique e ali reforçar a vocação colonial da nação. No preâmbulo ao diploma o ministro era claro:

accusados perante o mundo de povo inerte e sem aptidão colonizadora [...], precisâmos mostrar que não nos fallece a coragem para os emprehendimentos grandiosos, nem se nos entibia o animo para operar a grande obra da nossa restauração colonial (COLLECÇÃO OFFICIAL DE LEGISLAÇÃO PORTUGUEZA, 1891, p. 555).

Para o fazer, era mister ligar os diversos portos moçambicanos (Lourenço Marques, Beira, Quelimane, Inhambane, Tungue ou Pemba) por caminho de ferro até ao sertão. Assim que este ambicioso projeto se concretizasse, "ninguém nos poderá contestar a soberania da África oriental” (COLLECÇÃO OFFICIAL DE LEGISLAÇÃO PORTUGUEZA, 1891, p. 555).

Igual prevenção se estendia à contracosta. Sobretudo "hoje, que se põe em duvida o nosso dominio em alguns pontos de Africa [... ], urge que tratemos de construir linhas ferreas" (DIAS, 1890, p. 75) - escrevia o engenheiro Pereira Dias -, como, por exemplo, o caminho de ferro de Moçâmedes ao Lubango, considerado pela Junta Consultiva do Ultramar "mais uma evidente e irrecusavel affirmação da soberania de Portugal” na região (JUNTA CONSULTIVA DO ULTRAMAR..., 10 agosto 1899).

Contudo, este potencial identitário do caminho de ferro podia ser posto em causa se a sua implementação fugisse ao controlo nacional, uma questão que nunca foi muito bem resolvida pelas autoridades nacionais.

A vida da linha de Ambaca, por exemplo, ficou sempre marcada pela influência dos obrigacionistas ingleses da companhia que a construíra e operava. Uma vez que o caminho de ferro não produzia rendimento suficiente para pagar os juros das obrigações, os obrigacionistas, nos termos do contrato, podiam tomar conta da propriedade da linha. Nesta situação o caminho de ferro, poderoso instrumento de soberania nacional, poderia desempenhar o papel oposto e transformar-se numa ameaça a essa mesma soberania. 
Para o evitar, os sucessivos governos tomaram diversas medidas que garantiam 0 pagamento dos juros dos títulos de dívida (GUIMARÃES, 1983).

O caminho de ferro da Beira tornou-se um caso paradigmático desta situação. A linha fora construída, no rescaldo do Ultimato, por uma companhia britânica, praticamente sem qualquer supervisão das autoridades portuguesas (NAVARRO, 2018). Em 1896, o oficial do Exército português, Aires Ornelas, ao escoltar um corpo militar britânico à Rodésia (atual Zimbabwe), descrevia o caminho de ferro em tons deprimentes: na exploração, falava-se inglês; as medidas usadas eram as imperiais (pé, jarda, milha); a maior parte das terras limítrofes à via pertencia a britânicos. A ferrovia era “verdadeira via dolorosa desde a Beira á fronteira”. A situação era intricada, pois, se por um lado, se antevia "difficil tornar de facto portugueza uma região que hoje apenas o é no nome" (ORNELAS, 1896, p. 264), por outro lado, a companhia inglesa contribuía para o desenvolvimento comercial da província (como vimos), não sendo portanto boa política "pôr entraves ao que no fundo está facilitando o commercio e a civilisação de Africa" (COPIA..., p. 176).

Por estas razões, na década de 1890, o reforço da soberania passou a ser um argumento muito frequentemente trazido à colação sempre que um empreendedor ou um ministro requeria autorização ao parlamento para construir um caminho de ferro em qualquer parte do Império português (A QUESTÃO..., 1912, p. 17; AREZ, 5 março 1911; BALEN, 5 dezembro 1890; DOCUMENTOS..., 1912, p. 18-25; LIMA, 17 julho 1914; PORCHERON; VORSTER, 9 maio 1891; NAVARRO, 2018). Pelas mesmas razões, no início do século XX, os negócios em torno das concessões das linhas de Benguela e Suazilândia envolveram-se em polémica precisamente por abrir as colónias à interferência britânica. O então ministro da Marinha e Ultramar, Teixeira de Sousa, recorreu ao expediente de exigir verbas exorbitantes como depósitos de garantia para afastar os interessados. Porém, se o empreendedor australiano interessado na linha da Suazilândia, Walter "Karri" Davies, quando confrontado com a proposta do ministro, "hardly believed his own ears" (LANSDOWNE, 28 fevereiro 1903; PEREIRA, 2017), o escocês Robert Williams, interessado na linha de Benguela, cobriu a aposta de Teixeira de Sousa e depositou 100 mil libras para garantir a concessão do caminho de ferro (NAVARRO, 2018;). De facto, a 
situação nunca foi efetivamente resolvida e o potencial apropriador do caminho de ferro podia ser perfeitamente contraproducente se deixado sob controlo estrangeiro.

\subsection{O caminho de ferro como instrumento da civilização do negro}

Se bem que os objetivos de levar a civilização e o progresso a África, através do caminho de ferro, fosse um fim em si mesmo (e a tecnologia incorporasse integralmente aqueles dois conceitos), entendia-se na altura que a ação da ferrovia devia estender-se em particular à civilização do africano.

Nos contextos francês e inglês, África era vista como a ausência de civilização e os seus habitantes como criaturas obtusas, sem ambição nem espírito de iniciativa, incompreensivelmente alheados do sistema económico capitalista ocidental. A certeza da superioridade dos europeus era combinada com um sentido de responsabilidade para com as raças nativas tendo em vista a sua educação de acordo com os ideais europeus (CANNADINE, 2002; HALL, 2002; LEMAIRE; BLANCHARD, 2003).

Os portugueses partilhavam desta ideologia, considerando o negro um ser inferior, incapaz de potenciar os recursos do seu próprio continente. Só os brancos o podiam fazer, sendo, portanto, indispensável a sua presença em África, "sem a qual a prosperidade de qualquer colonia, e a propria civilisação do continente africano não é possivel" (JUNTA CONSULTIVA DE OBRAS PÚBLICAS E MINAS, 1890, p. 324) - concluía a Junta Consultiva de Obras Públicas em 1890. Na visão dos colonizadores portugueses, ao negro, restava apenas o papel passivo de ser civilizado, pela religião, pela instrução, pelas armas, mas sobretudo pelo trabalho e pela tecnologia (JERÓNIMO, 2015). Aliás, a própria religião tentou apropriar-se da tecnologia, sobretudo nos momentos inaugurais das linhas nos quais se ligava o progresso, tendo também a tecnologia atribuído a si própria algumas facetas moralizantes e indutoras de omnipotência, devoção e reverência normalmente associados à religiosidade (NOBLE, 1997. NYE, 1999. PEREIRA, 2018a).

De qualquer modo, a expectativa do uso do caminho de ferro como ferramenta de instrução, educação e civilização do africano está bem patente, por exemplo, nos escritos de Joaquim José Machado, o autor da citação com que abrimos este artigo e um dos 
principais protagonistas da aventura ferroviária nacional em África (NAVARRO, 2018). Ainda na década de 1870, este engenheiro arguia que no "século do vapor e da electricidade, a Europa não deve empregar para civilizar a África os processos seculares das sociedades antigas". A solução era outra, de cariz material e tecnológico:

muitos quilómetros de estradas e vias férreas é o que as nações cultas têm a fazer na África [...] para terminarem a escravidão da raça negra, promover o seu aperfeiçoamento moral e intelectual, e aproveitar as consideráveis riquezas naturais de tão extenso território (MACHADO apud NAVARRO, 2018, p. 320).

Esta retórica encontrava eco na imprensa da especialidade. Num número de 1905 da Gazeta dos Caminhos de Ferro, publicada quinzenalmente em Portugal, afirmava-se que

as estações ferroviárias e as casas de guarda são mais eficazes para a pacificação e domínio do que os fortes e redutos militares [...]. Não afugentam o indígena, atraem-no. Não o castigam, educam-no, aumentando-lhe o bem-estar, valorizam-lhe a sua riqueza, civilizam-no (apud NAVARRO, 2018, p. 463).

As estações representavam no século XIX aquilo que as catedrais configuravam em séculos anteriores (FAITH, 1991). Eram estruturas retóricas, demonstrando o poderio dos seus construtores (NYE, 1999; PEREIRA, 2018a). A importância da sua imponência visual foi um fator preponderante, por exemplo, na decisão de construir uma nova gare em Lourenço Marques, nos inícios do século XX. Muito embora a decisão se ficasse também a dever a questões logísticas (ligadas ao aumento do movimento na linha), respondia igualmente a quesitos de "decoro nacional”: a antiga estação era "verdadeiro ponto negro" na cidade, que "desprestigiava Portugal, «perante nacionais e estrangeiros», contrastando flagrantemente com estações congéneres" da África do Sul. Pelo contrário, a nova gare (figura 1) apresentava uma "imponência majestática" e “«certa grandeza de linhas como convém a obra tão importante»" (NAVARRO, 2012, p. 174, p. 178). A estação terminal de Moçâmedes, na cidade com o mesmo nome, embora não tão imponente como a de Lourenço Marques, transmitia de igual modo a solidez, austeridade e funcionalidade que o caminho de ferro prometia (figura 2 ). 
Figura 1 - Estação de Lourenço Marques em 1922

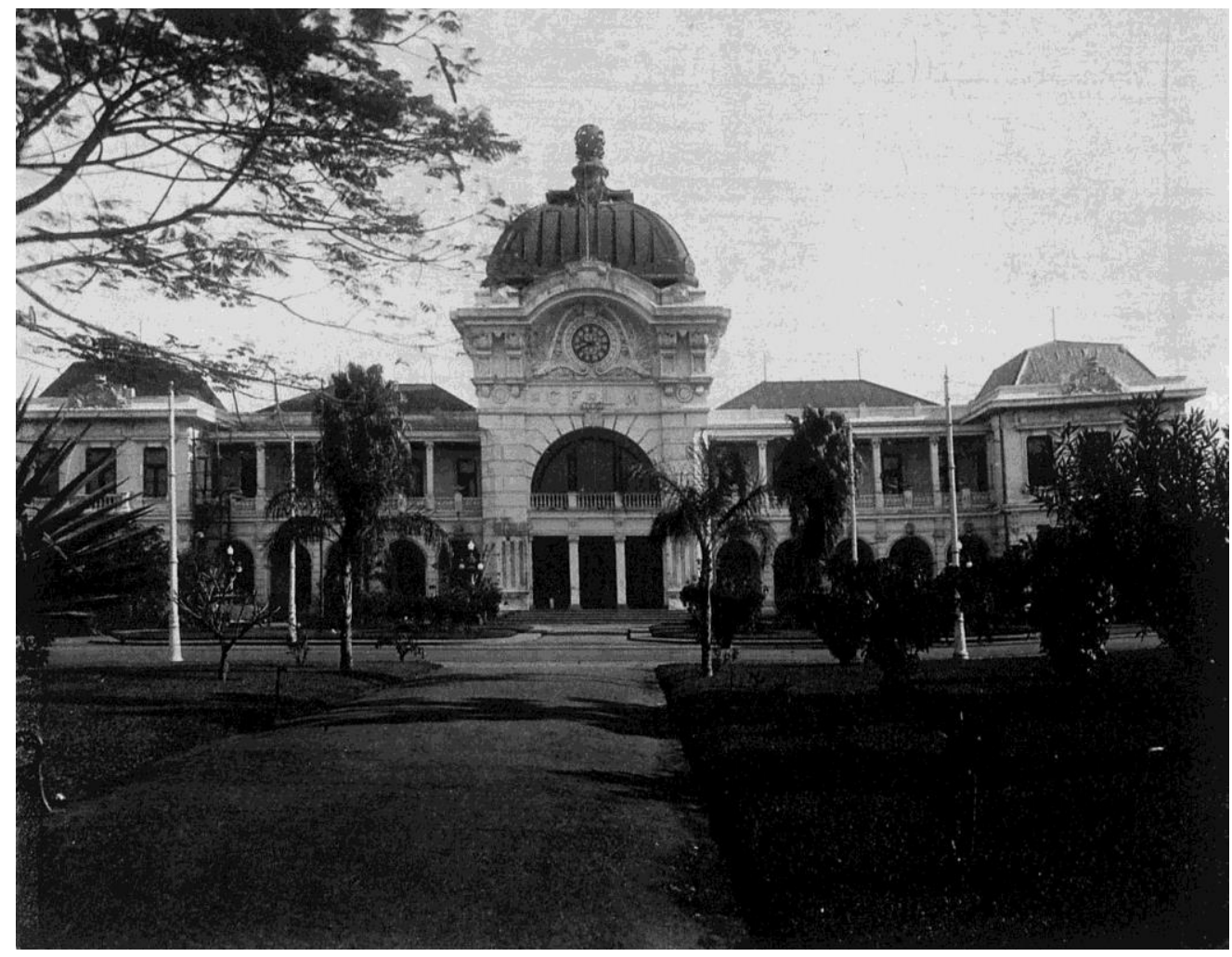

Fonte: LIMA, 1971, v. 1, p. 39

Figura 2 - Estação de Moçâmedes, em construção, em 1910

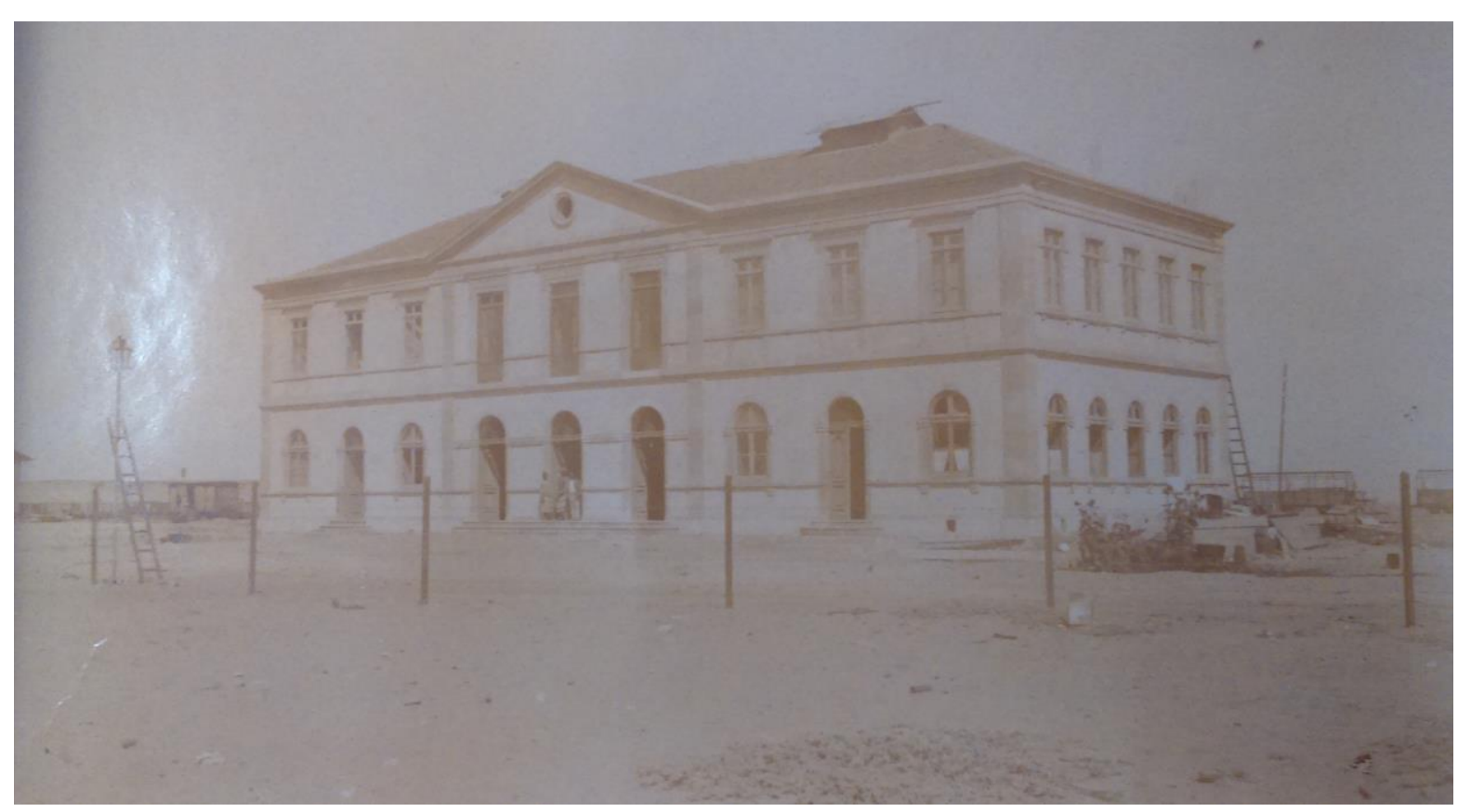

Fonte: CAMINHOS DE FERRO, MOÇÂMEDES, 1910-1916 
Contudo, o próprio progresso material tinha uma forte componente moral: o caminho de ferro era percecionado como um influente instrumento civilizador, um “desinfectante e um purificador moral”, do qual fugiam "todos os maus preconceitos, todas as reacções, toda a ignorância e a indolência, o crime e o vício" (Pedro Romano Folque, engenheiro fiscal da linha de Ambaca, apud NAVARRO, 2018, p. 279).

Esta ação civilizadora era sobretudo executada através do trabalho e na obrigação de labor imposta aos nativos. Na linha de Moçâmedes, por exemplo, "obrigar os Cumatos a dar braços para a construcção do caminho-de-ferro [...] hade concorrer para a sua civilisação" (OSÓRIO, 30 setembro 1907) - aconselhava o seu diretor de construção. Era assim imperativo e parte da missão civilizadora do caminho de ferro

fazer trabalhar aquele que não tem necessidades criadas, a quem a natureza fornece gratuitamente os meios de subsistência, a quem, enfim, a indolência e o alcoolismo mantinham num completo estado de embrutecimento (relatório da Companhia do Caminho de Ferro Através de África, concessionária da linha de Ambaca, apud NAVARRO, 2018, p. 276).

Figuras 3 e 4 - A instrução do negro pelo trabalho: aspetos da construção das linhas da Beira e de Moçâmedes

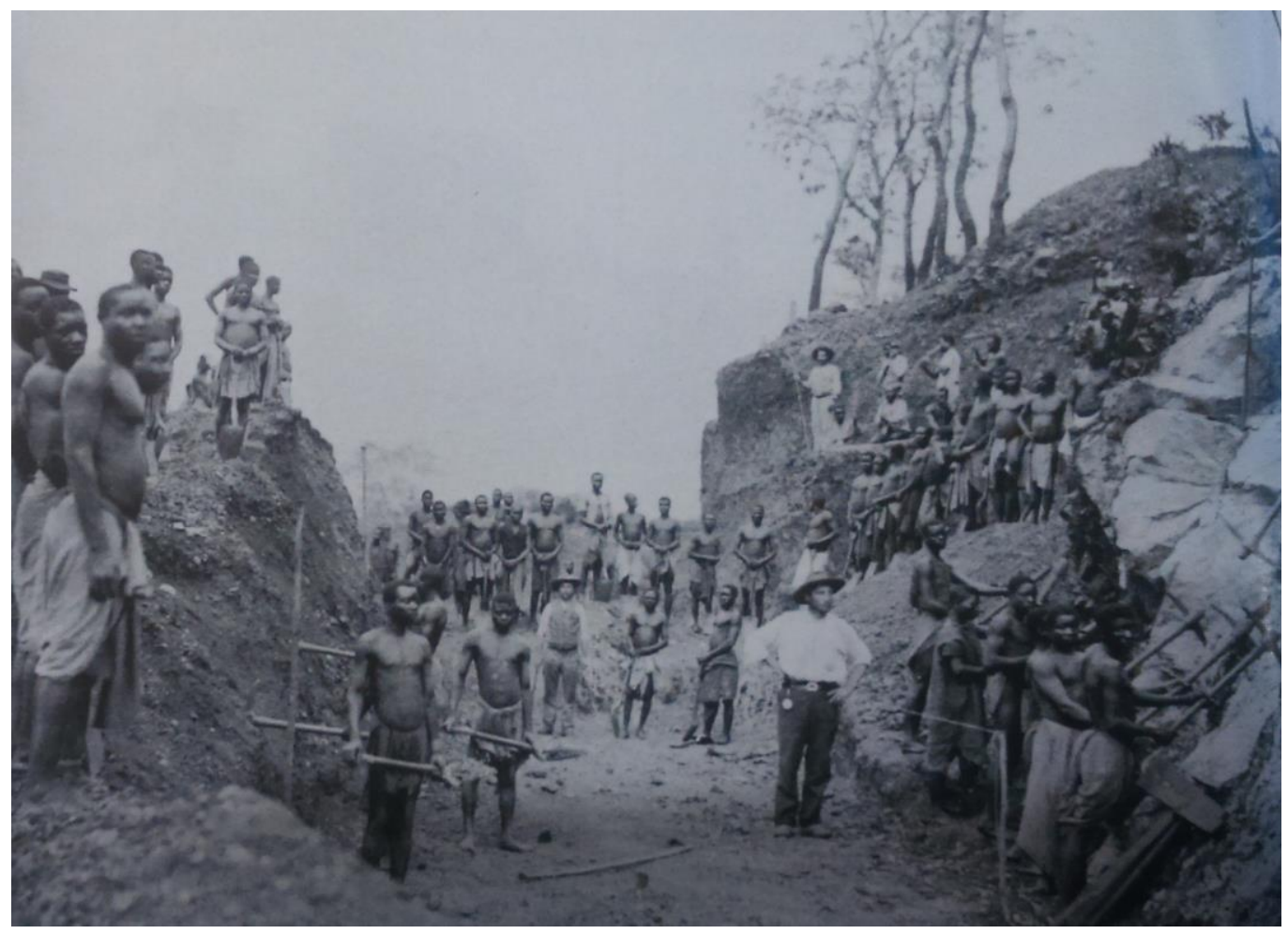




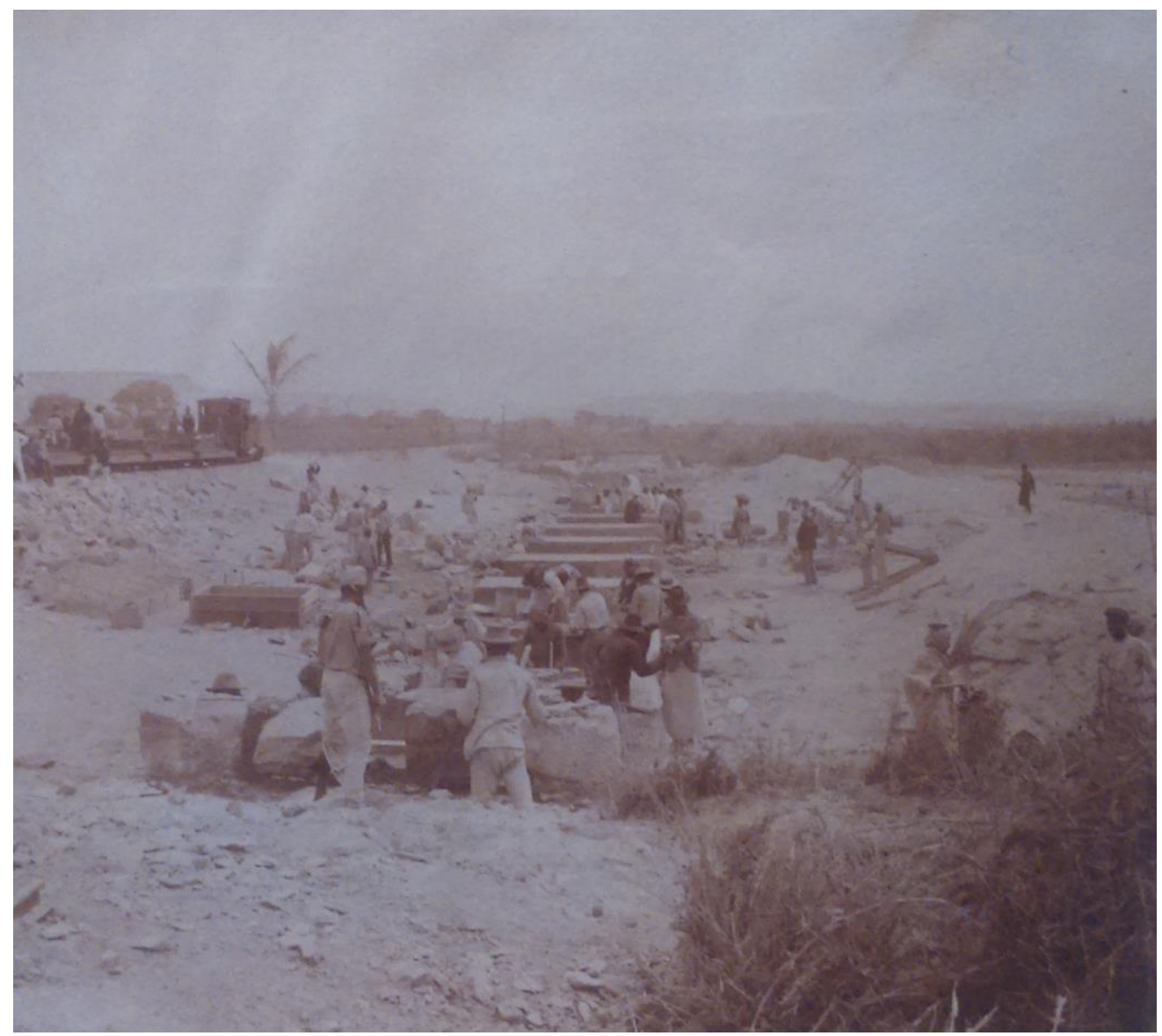

Fontes: BAXTER, 1998; CAMINHOS DE FERRO, MOÇÂMEDES, 1906-1908

O uso das linhas era também apresentado como terapêutica para a instrução do indígena. Citando novamente como exemplo a linha de Moçâmedes, a Junta Consultiva do Ultramar recomendava a criação de uma tarifa diferenciada, mais baixa, para o nativo para que este, "rude e ignorante, se habitue e affeiçoe a ser transportado em caminhode-ferro" (JUNTA CONSULTIVA DO ULTRAMAR..., 4 março 1907). Esperava-se assim que no médio/longo prazo, tudo isto contribuísse para a educação dos povos africanos, que, por sua vez, permitiria "preferir á guerra de exterminio contra os indigenas o instrumento economico do seu progresso e civilização" (CURTO, 26 janeiro 1905). Aliás, foi para obstar às revoltas e motins de Angola a partir de 1910 (PÉLISSIER, 1986) que se impôs a satisfação da "imperiosa necessidade de levar por meio de caminho de ferro a acção civilizadora àquelas isoladas e remotas paragens" (DOCUMENTOS..., 1912, p. 18-25). 


\section{Cultura material e paisagem tecnológica}

Em cada uma das fotografias do Douro torna-se possível ler uma paisagem tecnológica e científica recém-construída, uma tecnologia moderna de representação e o projecto de construção da imagem da nação oitocentista (MACEDO, 2012, p. 309).

O papel do caminho de ferro na promoção de uma cultura material em África deixou também marcas profundas na paisagem africana. Cortada a partir de então por carris, pontes, viadutos, estações, locomotivas e carruagens, que lhe emprestavam uma parte do seu sublime, a paisagem assumiu laivos de paisagem tecnológica.

No século XIX e inícios do século XX, a tecnologia não era encarada como uma violação da natureza ou da paisagem, mas sim como uma sua extensão. Ao se construírem paisagens tecnológicas, entendia-se que a natureza era dominada e deixaria de pertencer aos selvagens que a não sabiam aproveitar (NYE, 1999).

Fotografias da época contribuíram para a solidificação e divulgação desta transformação e para a construção de um retrato demonstrativo do esforço que Portugal fazia para civilizar África. Permitem ainda ilustrar alguns aspetos determinantes das paisagens tecnológicas e analisar as representações coevas que acarretavam (ver figuras 5 a 10$)$.

Figura 5 - Locomotiva sobre a ponte de Chicongene em 1887

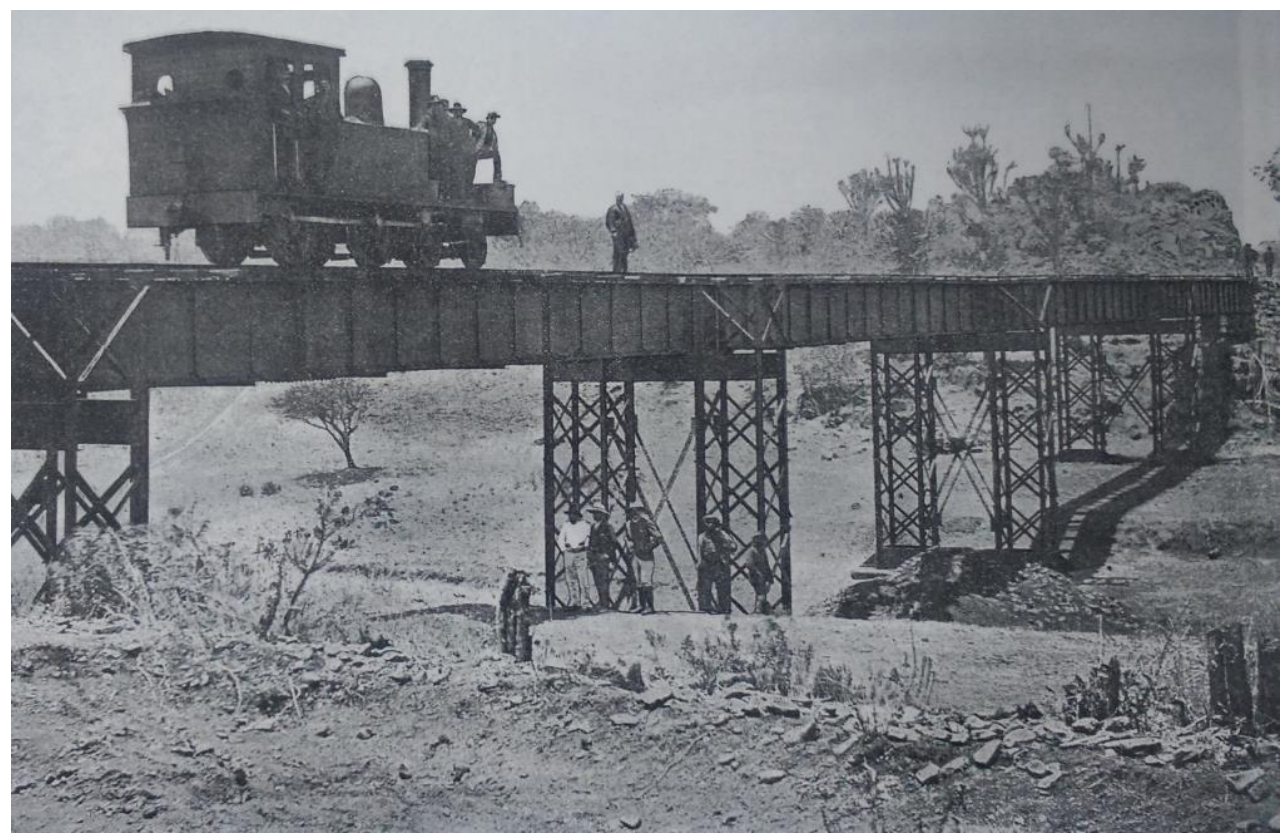

Fonte: MCMURDO; FOWLER, 1887 
Figura 6 - A linha da Beira na floresta de Amatongas (década de 1890)

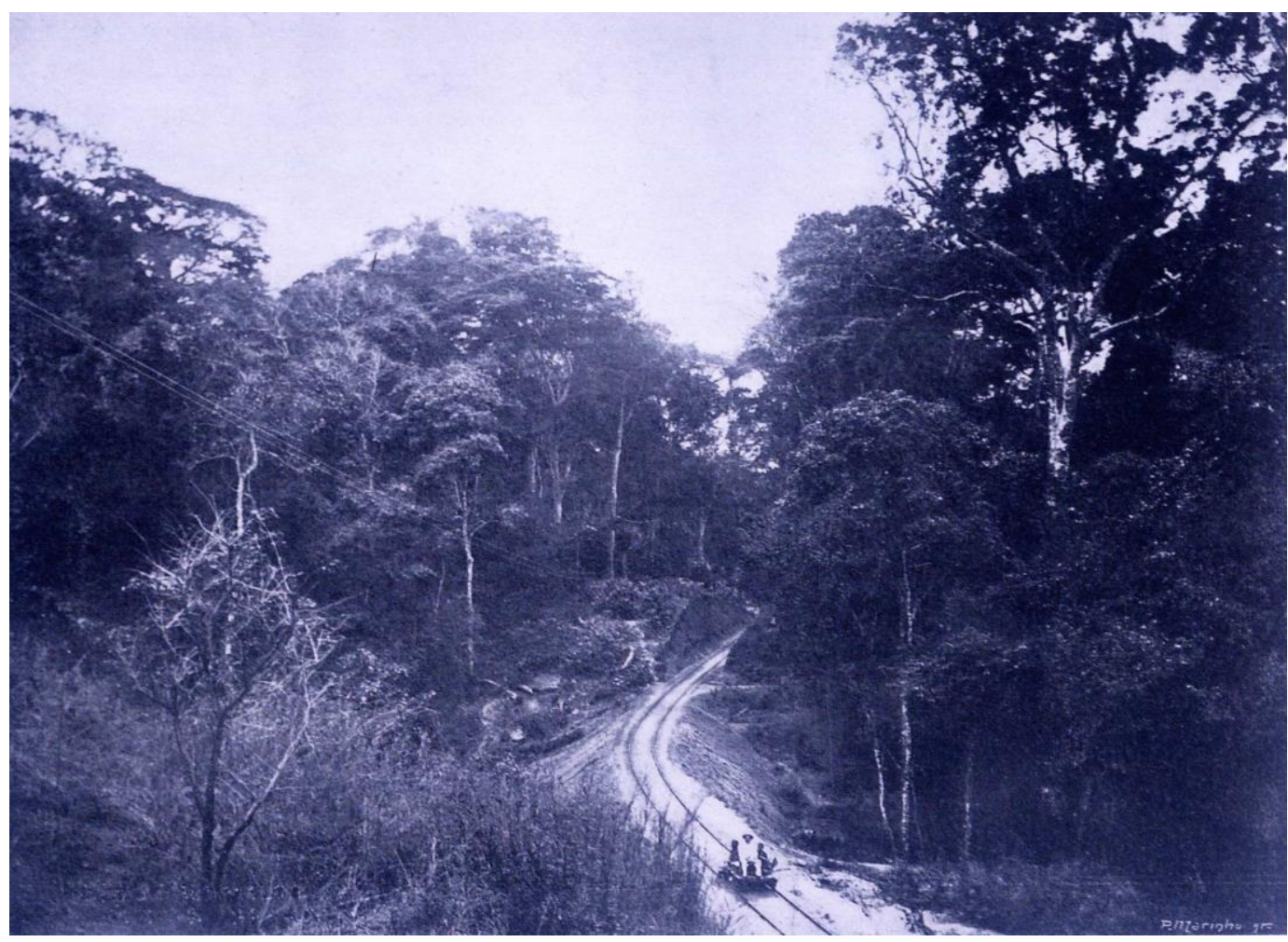

Fonte: O TERRITORIO..., 1902

Figura 7 - Toma de água e máquina na linha de Moçâmedes (1907)

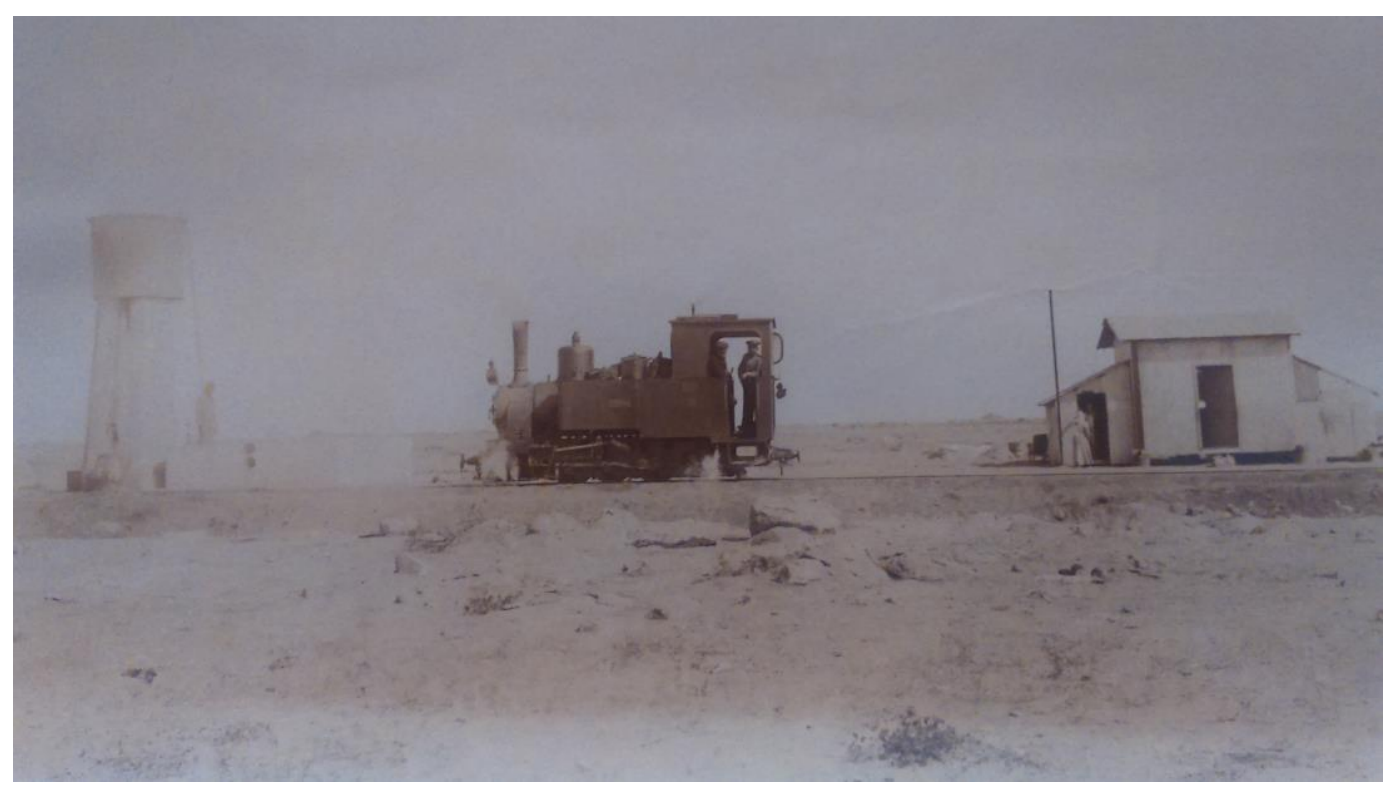

Fonte: CAMINHOS DE FERRO, MOÇÂMEDES, 1906-1908 
Figura 8 - Acampamento no caminho de ferro de Moçâmedes (1908)

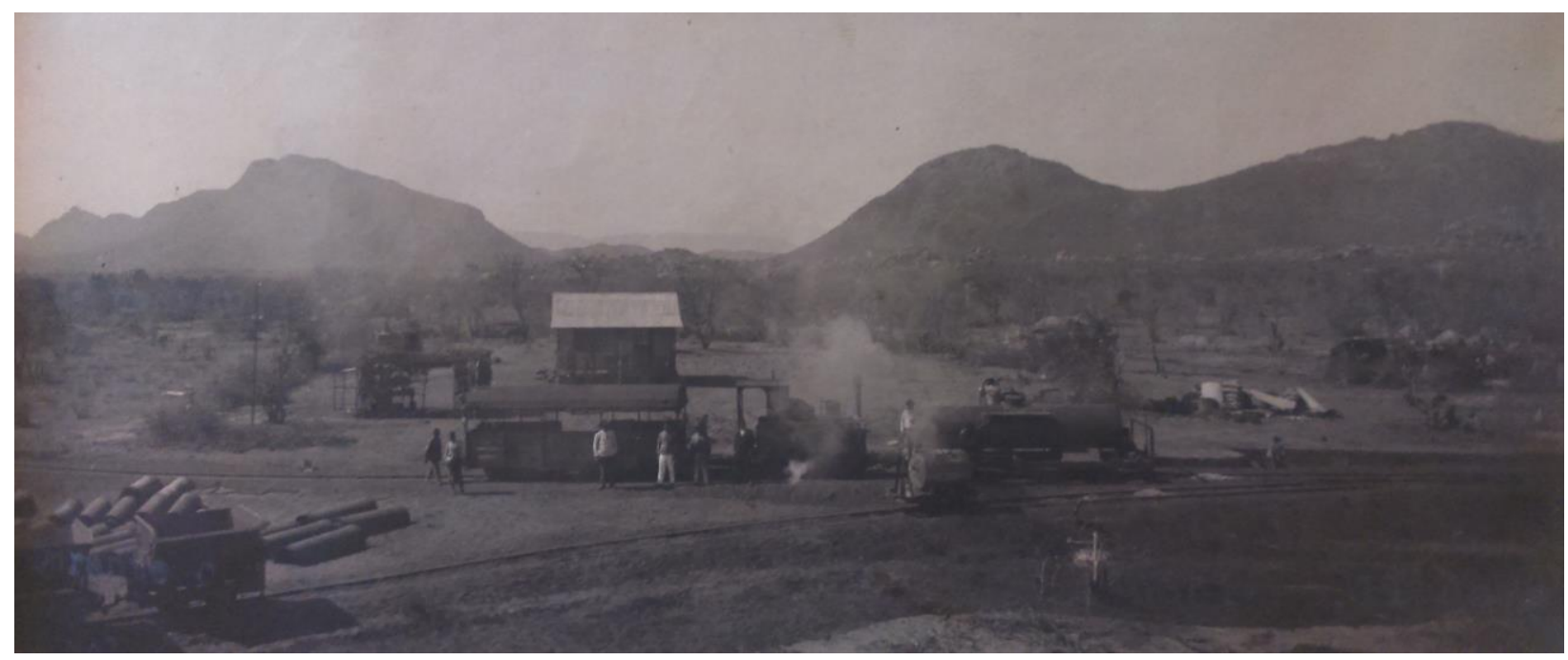

Fonte: CAMINHOS DE FERRO, MOÇÂMEDES, 1906-1908

Figura 9 - O viaduto do Lengue na linha de Benguela (1906)

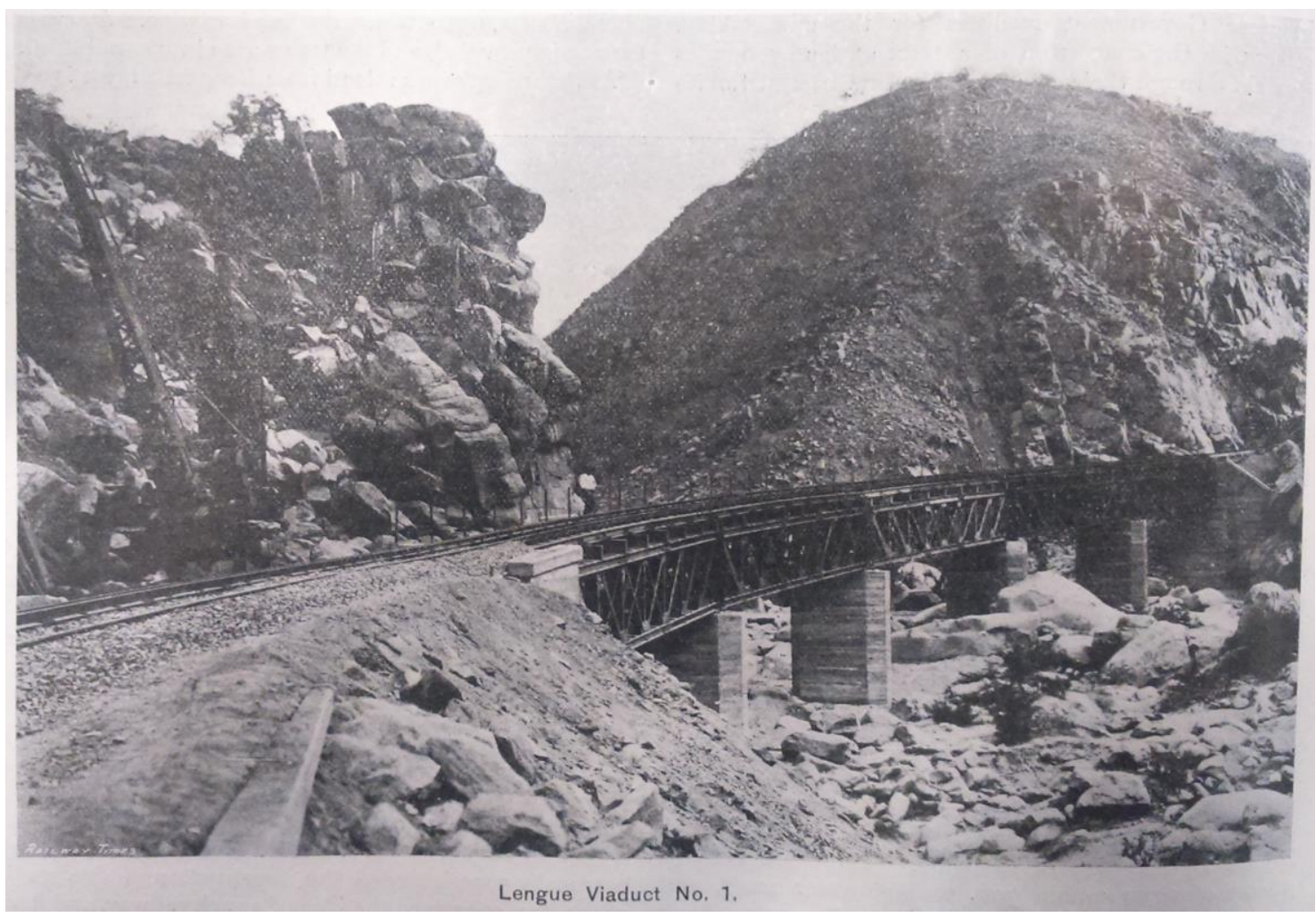

Fonte: THE RAILWAY TIMES, 30 março 1907, 329-332 
Figura 10 - Locomotiva sobre a ponte Comandante Álvaro Machado no desfiladeiro do Lengue na linha de Benguela (década de 1930)

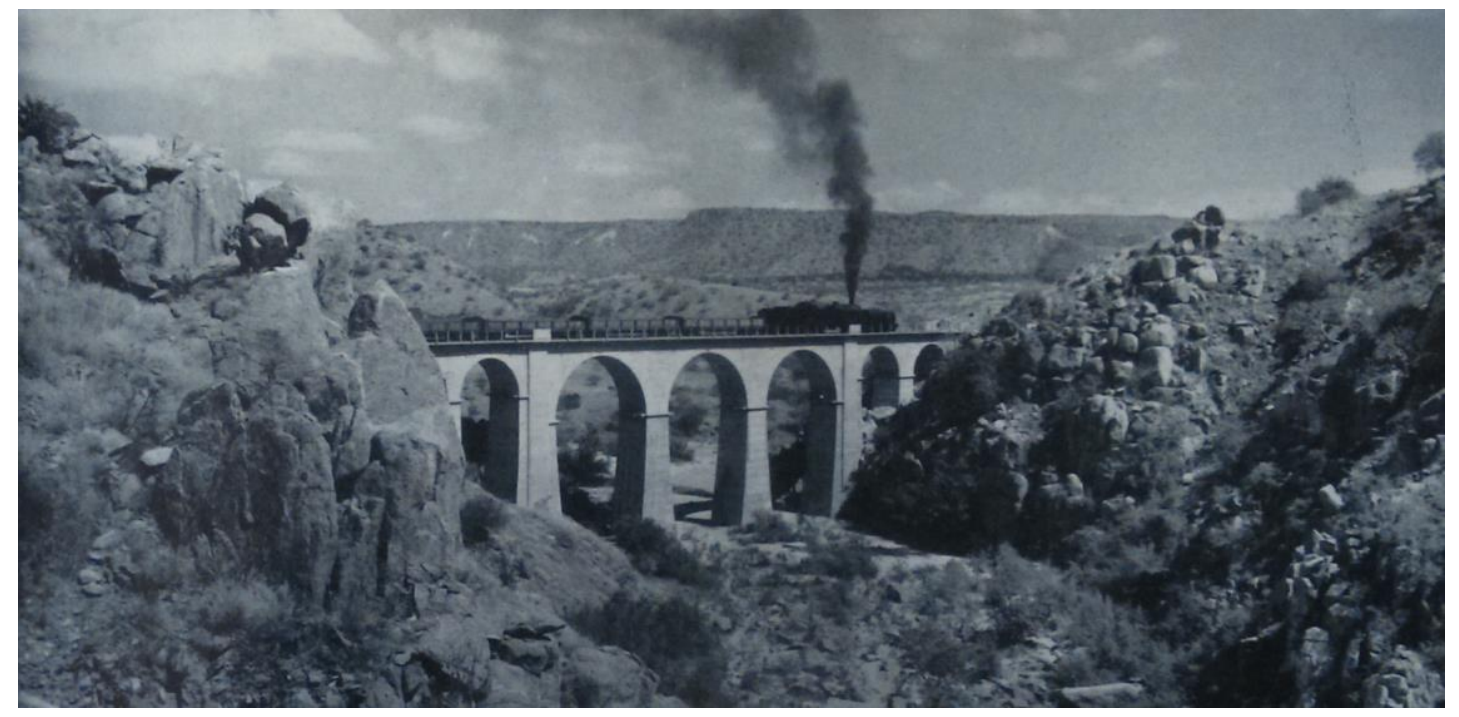

Fonte: BENGUELA..., 1960

As fotos analisadas têm dois aspetos em comum. Em primeiro lugar, em todas elas o caminho de ferro é representado como se albergado na perfeição pela paisagem. A partir de certa altura e noutros contextos, a fotografia foi usada na construção de uma representação quintessencial da natureza, "as though human civilization did not exist" (KELSEY, 2016, p. 81-90). Não era este o caso analisado. A tecnologia era publicitada, não como invadindo um espaço virginal, mas sim imiscuindo-se naturalmente na paisagem.

Em segundo lugar, a paisagem é apresentada na sua parte mais agreste e inóspita, enaltecendo assim a capacidade da ferrovia para vencer os obstáculos mais difíceis, domesticar a natureza e civilizar África. As figuras 6 e 7 são particularmente elucidativas deste aspeto: na primeira, a via-férrea é captada a entrar corajosamente na densa floresta de Amatongas, ao passo que na segunda a locomotiva aparece como único elemento vivo numa paisagem desértica.

Deste modo, passado e futuro eram ligados entre si, demonstrando o que era e o que viria a ser: o passado representado pela paisagem selvagem ou árida de África; o futuro pela locomotiva ou pelas pontes metálicas. A fotografia assumia-se assim como "a way of moving into the future by reorienting oneself to the past [...], a way to proclaim the emergence of a new sensibility about history and its consequences" (KELSEY, 2016, p. 80). 
Outro detalhe importante respeita à coexistência de elementos humanos e nãohumanos na paisagem, embora algumas das fotografias retratem apenas o elemento técnico (figura 10). A inclusão de figuras humanas junto das suas criações tecnológicas, além de servir de escala para medir a grandeza das novas infraestruturas, identificava os seus autores e elevava-os à categoria de pontas de lança do progresso. Um olhar mais cuidado denota que as figuras humanas estão rigorosamente a posar para a fotografia. Não estão no seu quotidiano laboral, mas simplesmente a marcar presença como responsáveis pelo novo elemento material da paisagem.

Tudo isto ia ao encontro e reforçava a mensagem que se pretendia passar através da construção de caminhos de ferro em África: a ferrovia e a nova cultura material por ela trazida representavam um processo evolutivo natural, o futuro e o domínio das forças da natureza, encetados pelas mãos de europeus, de brancos, de portugueses.

\section{Conclusão}

A construção de caminhos de ferro é normalmente associada a empreendimentos capitalistas buscando o lucro ou a iniciativas estatais de serviço público. Através da implementação da tecnologia ferroviária, ambos procuram potenciar as capacidades e aumentar a oferta de transporte em determinadas sociedades. Contudo, a ferrovia tem também importantes aspetos culturais e políticos, ligados à mensagem de modernidade que transmite, sobretudo no século XIX/inícios do século XX, mas em grande medida também ainda no século XXI - basta olhar para o revivalismo da construção ferroviária espoletado pela recente solução tecnológica dos comboios de alta velocidade (GIUNTINI, 2014).

Neste artigo, procuramos realçar estas últimas facetas - a importância política e cultural do caminho de ferro na África Portuguesa, mais do que a sua relevância económica ou eminentemente técnica - e seu contributo para a formação de uma cultura material nas colónias africanas nacionais ao serviço do imperialismo europeu sobre África. Simultaneamente, demonstramos como essa cultura espelhava a mentalidade das elites técnicas e políticas da época e sua crença na ciência e tecnologia. 
A imposição dessa nova cultura material através do caminho de ferro fez-se num duplo sentido: para o exterior e para o interior. Por um lado, deveria mostrar, perante as nações europeias, a vocação colonial de Portugal e o seu direito a uma presença em África. Por outro, perante as sociedades locais, evidenciava uma alegada superioridade técnica europeia e a sua legitimidade, não só tecnológica, mas sobretudo moral e civilizacional, para se impor sobre civilizações consideradas atrasadas e que deveriam ser trazidas para a modernidade através da tecnologia.

A construção de paisagens tecnológicas através do caminho de ferro e sua promoção através da fotografia contribuiu para aqueles dois objetivos. Imagens de ferrovias cruzando selvas ou panoramas desérticos ou de negros trabalhando sob supervisão europeia demonstrava que Portugal se empenhava em explorar os recursos de naturais de África, levar o progresso (a tecnologia e a ciência) ao derrogatoriamente chamado continente negro e civilizar o nativo (escondendo, porém, a realidade do trabalho forçado que as pessoas na Europa não queriam ver).

Com isto não queremos dizer que o caminho de ferro desempenhou este papel de forma completamente isolada. A ferrovia foi apenas uma das tecnologias colocadas ao serviço dos europeus no processo de colonização de África, tão importante como o quinino que os inoculava contra as doenças tropicais, o telégrafo que facilitava a administração do território ou as armas que pacificavam as tribos locais.

Pretendemos com este artigo contribuir para o argumento de Daniel Headrick sobre a marca que a tecnologia deixou nas civilizações africanas - talvez mais vincada que a deixada pelo cristianismo, capitalismo ou qualquer outra ideologia subjacente (HEADRICK, 1981) - para os paradigmas recentes de caracterização da sociedade portuguesa como profundamente influenciada pelos preceitos científicos e tecnológicos (MACEDO, 2012; SARAIVA, 2007), para a discussão sobre a importância da tecnologia na colonização portuguesa (DIOGO, 2009; DIOGO; LAAK, 2016; DIOGO; NAVARRO, 2018; NAVARRO, 2018) e para o debate sobre a importância das representações de tecnologia na formação de uma identidade nacional e na sua imposição sobre culturas diferentes. 
Reconhecemos, todavia, que a nossa análise é parcial por apenas incluir as perceções dos colonizadores. Em futuros desenvolvimentos deste estudo, importa ouvir as vozes e representações dos povos colonizados, de modo a obter uma apreciação mais completa destes fenómenos.

\section{Referências}

A QUESTÃO de Ambaca. Discurso proferido pelo sr. Freitas Ribeiro na Câmara dos Deputados na sessão de 14 de fevereiro de 1912. Conferencia realisada no dia 23 de fevereiro de 1912 no Centro Republicano Democrático pelo Major Norton de Matos. Lisboa: La Becarre, 1912.

ADAS, Michael. Dominance by design: technological imperatives and America's civilizing mission. Cambridge, MA: Harvard University Press, 2006.

ADAS, Michael. Machines as the measure of men: science, technology, and ideologies of western dominance. Ithaca, NY: Cornell University Press, 1989.

ALEGRIA, Maria Fernanda. Política ferroviária do fontismo: aspectos da construção e do financiamento da rede. Revista de História Económica e Social, Lisboa, n. 23, p. 43-64, 1988.

ALEXANDRE, Valentim; DIAS, Jill (Coords.). O império africano 1825-1890. In: SERRÃO, Joel; MARQUES, Oliveira (Eds.). Nova história da expansão portuguesa. v.10. Lisboa: Estampa, 1998.

AMARAL, Ferreira do. 0 caminho de ferro de Ambaca: parecer da comissão africana. Lisboa: Sociedade de Geografia, 1882.

AREZ, João Baptista de Almeida. Relatório entregue ao Ministério da Marinha e Ultramar. Caminhos Ferro, Luanda, Memória da construção do caminho de ferro de Luanda. Maço 4971 F. 5 março 1911.

BALEN, Barão de. Requerimento ao Ministério da Marinha e Ultramar. Miscelânea, Caminhos Ferro, Luanda, Malange e Mossâmedes. Maço 2670 1B (Arquivo Histórico Ultramarino). 5 dezembro 1890.

BAXTER, Antony. The Two Foot Gauge Enigma. Beira Railway, 1890-1900. Norwich: Plateway, 1998. 
BENGUELA Railway. Londres: Companhia do Caminho de Ferro de Benguela, 1960.

BLANCHARD, Pascal; LEMAIRE, Sandrine (Eds.). Culture coloniale: la France conquise par son empire. Paris: Autrement, 2003.

BOLETIM DA COMPANHIA DE MOÇAMBIQUE. Beira: Companhia de Moçambique, 18931910.

BOLETIM DO GOVERNO DO TERRITÓRIO DA COMPANHIA DE MOÇAMBIQUE. Beira: Companhia de Moçambique 1911-1915.

BOLETINS ESTATÍSTICOS DO MOVIMENTO COMERCIAL E MARÍTIMO NO TERRITÓRIO DA COMPANHIA DE MOÇAMBIQUE. Beira: Companhia de Moçambique, 1910.

BOLETINS ESTATÍSTICOS DO MOVIMENTO COMERCIAL E MARÍTIMO NO TERRITÓRIO DE MANICA E SOFALA. Beira: Companhia de Moçambique, 1908-1909.

BOUENE, Felizardo; SANTOS, Maciel. O modus vivendi entre Moçambique e o Transval (1901-1909). Um caso de «imperialismo ferroviário». Africana Studia, Porto, n. 9, p. 239269, 2006.

BREWER, Thomas Gibs. Carta ao Colonial Office. HM Treasury, T 1/17173 (The National Archives). 5 fevereiro 1878.

CAMINHOS de Ferro, Luanda, Ambaca, Malange e Mormugão, mapa da receita e despesa. Livro 927 1N (Arquivo Histórico Ultramarino). 1905-1916.

CAMINHOS de Ferro, Luanda. Peça 299 1H (Arquivo Histórico Ultramarino). 1912.

CAMINHOS de Ferro, Luanda. Peça 319 1H (Arquivo Histórico Ultramarino). 1902-1920.

CAMINHOS de Ferro, Malange e Moçâmedes, serviço de explorações. Maço 2565 1B (Arquivo Histórico Ultramarino). 1907-1916.

CAMINHOS de Ferro, Malange, mapas estatísticos da receita e da despesa. Maço 2564 1B (Arquivo Histórico Ultramarino). 1912.

CAMINHOS de Ferro, Malange. Maço 301 1H (Arquivo Histórico Ultramarino). 1907-1909.

CAMINHOS de Ferro, Moçâmedes, mapas da receita e despesa. Livro 942 1N (Arquivo Histórico Ultramarino). 1907-1914.

CAMINHOS de Ferro, Moçâmedes, receita e despesa. Maço 2473 1B (Arquivo Histórico Ultramarino). 1913. 
CAMINHOS de Ferro, Moçâmedes, receita e despesa. Maço 2508 1B (Arquivo Histórico Ultramarino). 1904-1908.

CAMINHOS de Ferro, Moçâmedes. Caixa 271 1H (Arquivo Histórico Ultramarino). 19101916.

CAMINHOS de Ferro, Moçâmedes. Caixa 275 1H (Arquivo Histórico Ultramarino). 19061908.

CAMINHOS de Ferro, Moçâmedes. Caixa 283 1H (Arquivo Histórico Ultramarino). 19131917.

CAMINHOS de Ferro, Moçâmedes. Caixa 292 1H (Arquivo Histórico Ultramarino). 19091910.

COLLECÇÃO OFFICIAL DE LEGISLAÇÃO PORTUGUEZA. Lisboa: Imprensa Nacional, 18431972.

COMISSÃO AFRICANA. O caminho de ferro de Ambaca. Boletim da Sociedade de

Geographia de Lisboa, Lisboa, n. 3, p. 143-170, 1882

COPIA de documentos officiaes trocados entre a Companhia de Moçambique e o Governo de Sua Magestade de Janeiro a Dezembro de 1895. Lisboa: Companhia Nacional Editora.

COSTA, Henrique César da Silva Barahona e. O problema das obras públicas nas suas relações com o progresso e desenvolvimento dos nossos domínios africanos. Boletim da Sociedade de Geographia de Lisboa, Lisboa, n. 4-6, p. 429-458, 1901.

CURTO, António Duarte Ramada. Carta ao Ministério da Marinha e Ultramar. Caminhos de Ferro, Mossâmedes. Maço 278 1H (Arquivo Histórico Ultramarino). 26 janeiro 1905.

DANT, Tim. Material culture in the social world: values, activities, lifestyles. Filadélfia, PA: Open University Press, 1999.

DAY, John R. Railways of Southern Africa. Londres: Arthur Barker, 1963.

Diario da Camara dos Deputados, vários anos.

DIARIO DO GOVERNO. Lisboa: Imprensa Nacional, 1820-1913.

DIAS, João José Pereira. O Caminho de Ferro de Mossamedes. Revista de Obras Publicas e Minas, Lisboa, n. 255-256, p. 62-75, 1890 
DIOGO, Maria Paula. Domesticating the wilderness: portuguese engineering and the occupation of Africa. In: MATOS, Ana Cardoso de, GRELON, André, Irina Gouzévitch e Maria Paula Diogo (Eds.). Jogos de identidade profissional: os engenheiros entre a formação e a acção. Lisboa: Colibri, 2009, p. 471-482.

DIOGO, Maria Paula; LAAK, Dirk van. Europeans globalizing: mapping, exploiting, exchanging. Basingstoke: Palgrava MacMillan, 2016.

DIOGO, Maria Paula; NAVARRO, Bruno J. Re-designing Africa: railways and globalization in the era of the new imperialism. In: PRETEL, David; CAMPRUBÍ, Lino (Eds.). Technology and globalisation: networks of experts in world history. Basingstoke: Palgrave MacMillan, 2018, p. 105-128.

DIVALL, Colin. Railway imperialisms, railway nationalisms. In: BURRI, Monika; ELSASSER, Killian; GUGERLI, David (Eds.). Die internationalität der Eisenbahn 1850-1970. Zurique: Chronos, 2009, p. 195-209.

DOCUMENTOS relativos à questão de Ambaca. Lisboa: Imprensa Nacional; Ministério das Colónias, 1912.

ELTON, Consul. Carta a Lord Derby. Colonial Office, CO 879/12/4 (The National Archives). 17 julho 1875

ESTATísTICA dos Caminhos de Ferro das Colónias Portuguesas de 1888 a 1911. Lisboa: Tipografia Eduardo Rosa; Ministério das Colónias, 1913.

FAITH, Nicholas. The world the railways made. Nova York, NY: Carroll \& Graph, 1991.

GIUNTINI, Andrea. Will railway save Europe?: a short history of high-speed trains. In: MATOS; Ana Cardoso de ; PINHEIRO, Magda (Eds.). História, património e infraestruturas do caminho de ferro: visões do passado e perspetivas do futuro. Lisboa: CEHC-IUL, 2014, p. 45-62.

GUIMARÃES, Ângela. Le chemin de fer de Luanda a Ambaca. African Economic History, Madison, WI, n. 12, p. 109-124, 1983.

GUIMARÃES, Ângela. Uma corrente do colonialismo português: a sociedade de geografia de Lisboa. Porto: Horizonte, 1984.

HALL, Catherine. Civilising subjects: metropole and colony in the english imagination 1830-1867. Chicago, IL: The University of Chicago Press, 2002.

HEADRICK, Daniel. Power over peoples: technology, environments, and western imperialism, 1400 to the present. Princeton, NJ: Princeton University Press, 2010. 
HEADRICK, Daniel. The tools of empire: technology and european imperialism in the nineteenth century. Oxford: Oxford University Press, 1981.

HOBSBAWM, Eric. A era das revoluções (1798-1848). Lisboa: Presença, 1982.

HOBSBAWM, Eric. A era do capital (1848-1875). Lisboa: Presença, 1979.

JACKSON, John Brinckerhoff. Discovering the vernacular landscape. Yale, CT: Yale University Press, 1984.

JUNTA CONSULTIVA DE OBRAS PÚBLICAS E MINAS. Caminho de Ferro de Moçâmedes ao Bihé. Parecer da junta consultiva de obras publicas e minas sobre o ante-projecto das secções entre Mossamedes e o alto da serra da Chella. Revista de Obras Publicas e Minas, Lisboa, n. 249-250, p. 317-327, 1890

JUNTA CONSULTIVA DE ULTRAMAR. Parecer ao Ministério da Marinha e Ultramar. Caixa $2791 \mathrm{H}$ (Arquivo Histórico Ultramarino). 10 agosto 1899

JUNTA CONSULTIVA DE ULTRAMAR. Parecer ao Ministério da Marinha e Ultramar. Maço 278 1H (Arquivo Histórico Ultramarino). 4 março 1907.

KÄRRHOLM, Mattias. Retailising space: architecture, retail and the territorialisation of Public Space. Burlington: Ashgate, 2012.

KASSON, John. Civilizing the machine: technology and republican values in America, 17761900. Nova York, NY: Grossman, 1976.

KELSEY, Robin. Is landscape photography? In: DOHERTY, Gareth; WALDHEIM, Charles (Eds.). Is landscape...? : essays on the identity of landscape. Londres: Routledge, 2016, p. 71-92.

KERR, lan J. Engines of change: the railroads that made India. Londres: Praeger, 2007.

KERR, lan J. Representation and representations of the railways of colonial and postcolonial South Asia. Modern Asian Studies, Londres, v. 37, n. 2, p. 287-326, Spring 2003.

LAAK, Dick van. Detours around Africa: the connection between developing colonies and integrating Europe. In: BADENOCH, Alexander; FICKERS; Andreas. Materializing Europe: transnational infrastructures and the project of Europe. Basingstoke: Palgrave-MacMillan, 2010, p. 27-43.

LANSDOWNE, Marquês de. Carta ao Colonial Office. Foreign Office, FO 63/1444 (The National Archives), 28 fevereiro 1903 
LATOUR, Bruno. Politics of nature: how to bring the sciences into democracy. Cambridge, MA: Harvard University Press, 2004.

LEE, Robert. Potential railway world heritage sites in Asia and the Pacific. Working Papers in Railway Studies, York, n. 5, p. 14-28, 1999.

LEGISLAÇÃO e disposições regulamentares sobre caminhos de ferro ultramarinos. Lisboa: Imprensa Nacional, 1895-1908.

LEMAIRE, Sandrine; BLANCHARD, Pascal. Exhibitions, expositions, médiatisation et colonies. In: BLANCHARD, Pascal; LEMAIRE, Sandrine. Culture coloniale: la France conquise par son Empire. Paris: Autrement, 2003, p. 43-54.

LIMA, Alfredo. História dos caminhos de ferro de Moçambique. Lourenço Marques: Administração dos Portos e Caminhos de Ferro de Moçambique, 1971.

LIMA, Alfredo Augusto Lisboa de. Carta ao Ministro dos Negócios Estrangeiros. Caminhos de Ferro, Mossâmedes. Caixa 278 1H, vol. 1, proc. 14. 17 julho 1914

MACEDO, Marta Coelho de. Projectar e construir a nação: engenheiros e território em Portugal. Lisboa: Imprensa de Ciências Sociais, 2012.

MARTINS, Leonor Pires. Um império de papel: imagens do colonialismo português na imprensa periódica ilustrada (1875-1940). Lisboa: Edições 70, 2012.

MATOS, Patrícia. Images of Africa?: portuguese films and documentaries related to the former colonies in Africa (first half of the $20^{\text {th }}$ century). Comunicação e Sociedade, Braga, n. 29, p. 175-196, 2016.

McMURDO, Edward; FOWLER, C. S. Views of Lourenço Marques (Delagoa Bay) and transvaal railway. [S. I.: S. n.], 1887.

MESQUITA, João. Dados estatisticos para o estudo das pautas de Angola. Luanda: Imprensa Nacional, 1918.

MISCELÂNEA, Caminhos de Ferro, S. Tomé, Caminhos de Ferro L. M, Caminhos de Ferro, Mossâmedes, Malange, Estatísticas. Maço 2756 1B (Arquivo Histórico Ultramarino). 18881914 .

MISCELÂNEA, Direcção dos Caminhos Ferro, Lourenço Marques, Luanda-Ambaca, Mormugão. Maço 2673 1B (Arquivo Histórico Ultramarino). 1889-1923.

MITCHELL, W. J. T. Landscape and power. Chicago, IL: The Chicago University Press, 2002. 
NAVARRO, Bruno. A estação central de Maputo no contexto das politicas de preservação do património edificado de Moçambique: estudo de caso. Historiæ, Rio Grande, v. 3, n. 1, p. 171-200, Verão 2012.

NAVARRO, Bruno J. Um império projectado pelo «silvo da locomotiva»: o papel da engenharia portuguesa na apropriação do espaço colonial africano Angola e Moçambique (1869-1930). Lisboa: Colibri, 2018.

NOBLE, David. The religion of technology: the divinity of man and the spirit of invention. Nova York, NY: Alfred Knopf, 1997.

NYE, David. American technological sublime. Cambridge, MA: The MIT Press, 1999.

O TERRITORIO de Manica e Sofala e a administração da companhia de Moçambique (18921900). Lisboa: Companhia de Moçambique; Companhia Nacional, 1902.

ORNELAS, Aires de. O caminho-de-ferro da Beira e a passagem das tropas imperiaes inglezas em Julho de 1896. Revista do Exercito e da Armada, Lisboa, n. 7, p. 257-264, 1896.

OSBORNE, Brian S. The iconography of nationhood in canadian art. In: COSGROVE, Denis; DANIELS, Stephen. The iconography of landscape: essays on the symbolic representation, design and use of past environments. Cambridge, MA: Cambridge University Press, 1988, p. 1-10.

OSÓRIO, Cândido. Relatório de construção e exploração da linha de Moçâmedes. Caminhos de Ferro, Mossâmedes. Maço 275 1H (Arquivo Histórico Ultramarino). 30 setembro 1907

PAKENHAM, Thomas. The scramble for Africa, 1876-1912. Londres: The Folio Society, 2011.

PAYNTON, Philip. An English cross-country railway: rural England and the cultural reconstruction of the Somerset and Dorset Railway. Working Papers in Railway Studies, York, n. 2, p. 17-25, 1996.

PÉLISSIER, René. História das campanhas de Angola: resistência e revoltas (1845-1941). Lisboa: Estampa, 1986.

PÉLISSIER, René. Les campagnes coloniales du Portugal 1844-1941. Paris: Pygmalion, 2004.

PEREIRA, Hugo Silveira. Abordagem ao «tecnologismo»: tecnologia e religião no Portugal da Regeneração. Revista de História das Ideias, Coimbra, n. 36, p. 123-145, 2018 a. 
PEREIRA, Hugo Silveira. Identidade e tecnologia: o caminho de ferro da Suazilândia (19001914). Anais de História de Além-Mar, Lisboa, n. 18, p. 143-176, 2017.

PEREIRA, Hugo Silveira. O caminho de ferro da Beira em Moçambique (1890-1914): entre antagonismo tecnodiplomático e simbiose económica. Análise Social, Lisboa, no prelo, 2019.

PEREIRA, Hugo Silveira. O caminho de ferro de Moçâmedes: entre projeto militar, instrumento tecnodiplomático e ferramenta de apropriação colonial (1881-1914). Revista de História da Sociedade e da Cultura, Coimbra, n. 18, p. 157-183, 2018b.

PORCHERON, H; VORSTER, B. J. Requerimento ao Ministério da Marinha e Ultramar. Caminhos Ferro, Sofala até aos Rios Busis e Púnguè, Caminhos Ferro, Zambézia. Maço 491 1F (Arquivo Histórico Ultramarino). 9 maio 1891.

QUESTÃO do Caminho de Ferro de Lourenço Marques entre Portugal, E. U. A. e Inglaterra, Caminhos de Ferro, Luanda, Malange, Mossâmedes. Maço 2526 1B (Arquivo Histórico Ultramarino). 1887-1918.

SARAIVA, Tiago. Inventing the technological nation: the example of Portugal (1851-1898). History and Technology, Filadélfia, PA, v. 23, n. 3, p. 263-273, Fall 2007.

SCHOT, Johan; SCRANTON, Philip. Making Europe: an introduction to the series. In: KOHLRAUSCH, Martin ; TRISCHLER, Helmuth. Building Europe on expertise: innovators, organizers, networkers. Basingstoke: Palgrave-MacMillan, 2014, p. IX-XVI.

SCHUELER, Judith. Travelling towards the 'mountain that has borne a state'. The Swiss Gotthard Railways. In: VAN DER VLEUTEN, Erik; KAIJSER, Arne. Networking Europe: transnational infrastructures and the shaping of Europe, 1850-2000. Sagamore Beach, MA: Science History Publications, 2006, p. 71-96.

SHILS, Edward. Center and periphery: essays in macrosociology. Chicago, IL: The University of Chicago Press, 1975.

SIMÕES, Ana; CARNEIRO, Ana; DIOGO, Maria Paula. Introductory remarks. In: SIMÕES, Ana; CARNEIRO, Ana; DIOGO, Paula. Travels of learning: a geography of science in Europe. Dordrecht: Kluwer, 2003, p. 1-14.

SWARTZ, David. Culture \& power: the sociology of Pierre Bourdieu. Chicago, IL: The University of Chicago Press, 1997.

The Railway Times, 1881, 1907. 
VAN DER VLEUTEN, Erik; ANASTASIADOU, Irena; LAGENDIJK, Vincent; SCHIPPER, Frank. Europe's system builders: the contested shaping of transnational road, electricity and rail networks. Contemporary European History, Cambridge, MA, vol. 16, n. 3, 321-347, Outono 2007.

VAN DER VLEUTEN, Erik. Understanding network societies: two decades of large technical system Studies. In: VAN DER VLEUTEN, Erik; KAIJSER, Arne. Networking Europe: transnational infrastructures and the shaping of Europe, 1850-2000. Sagamore Beach, MA: Science History Publications, 2006, p. 279-314.

WOODWARD, Ian. Understanding material culture. Gateshead: Sage, 2007. 